\title{
Factors Affecting the Distribution of Atyid Shrimps in Two Tropical Insular Rivers ${ }^{1}$
}

\author{
Trina Leberer ${ }^{2,3}$ and Stepben G. Nelson ${ }^{2,4}$
}

\begin{abstract}
We investigated factors affecting distribution of atyid shrimps, common inhabitants of insular freshwater ecosystems. Several abiotic and biotic variables were measured to determine their influence on atyid shrimp densities in two streams on the western Pacific island of Guam. Randomly selected sites, composed of three habitat types (riffles, runs, and pools), were surveyed in the rainy and dry seasons. We made visual counts of instream fauna in $2-\mathrm{m}^{2}$ quadrats within each site. Various statistical analyses suggested that habitat type is a major factor affecting atyid distribution on Guam. However, results of a transplant experiment, conducted to test the effect of predators on atyid distribution directly, were noteworthy: no atyids remained in pools containing the transplanted jungle perch Kublia rupestris in the field. Our data indicate that both environmental factors and faunal interactions may be important influences on atyid distribution.
\end{abstract}

Atyid shrimps are common in the freshwater habitats of oceanic islands. There are seven recorded species of stream atyids on the western Pacific island of Guam: Atyoida pilipes (Newport, 1847), Atyopsis spinipes (Newport, 1847), Caridina longirostris (Milne-Edwards, 1837), Caridina nilotica (Roux, 1833), Caridina serratirostris de Man, 1892, Caridina typus Milne-Edwards, 1837, and Caridina weberi de Man, 1892. All except Atyopsis spinipes were seen during this study. Caridina longirostris and $C$. weberi are new records for Guam (this study). All of these species are native to Guam, but none is endemic. Like most other atyids (Shokita 1976, Benzie 1982), all those occurring in the rivers of Guam are amphidromous, with their larvae drifting downstream to the ocean, developing in the

\footnotetext{
${ }^{1}$ Manuscript accepted 5 January 2001.

2 University of Guam Marine Laboratory, UOG Station, Mangilao, Guam 96923.

${ }^{3}$ Current address: Department of Agriculture, Division of Aquatic and Wildlife Resources, 192 Dairy Road, Mangilao, Guam 96923.

${ }^{4}$ Current address: Environmental Research Laboratory, University of Arizona, $2601 \mathrm{E}$. Airport Drive, Tucson International Airport, Tucson, Arizona 85706-6985.
}

Pacific Science (2001), vol. 55, no. 4:389-398

(C) 2001 by University of Hawai'i Press

All rights reserved plankton, and migrating back upstream as juveniles. Although some previous studies have addressed the postlarval ecology of atyids in various geographical locations (Hart 1981, Carpenter 1983, Dudgeon 1985, de Silva 1988, Crowl and Covich 1994), less information is available from the tropical Pacific Region. Couret (1976) provided a comprehensive summary of the biology of the Hawaiian atyid Atyoida bisulcata Randall, 1840, including aspects of its ecology. Bright (1979) included some ecological information in his study of freshwater ecosystems in Palau. EllisNeill (1987) concluded that current velocity and a greater abundance of leaf litter are important influences of invertebrate distribution (including atyids) on Guam. The ecology of atyids on Yap was briefly mentioned in Bright (1989).

In this study, we addressed the following question: Which environmental and faunal factors affect the distribution of atyids on Guam? We analyzed several abiotic and biotic variables, including season, reach, habitat, $\mathrm{pH}$, water temperature, maximum depth, canopy cover, substrate composition, abundance of aquatic vegetation, current velocity, and densities of other riverine fauna. Preliminary observations suggested that predation was an important faunal factor influencing atyid distribution. We examined predation in 
two ways. First, we compared densities of atyid species with potential predator densities in a correlation analysis. In the streams of Guam, potential predators include the jungle perch Kublia rupestris (Lacépède, 1802); the freshwater eel Anguilla marmorata Quoy \& Gaimard, 1824; the sleeper goby Eleotris fusca (Bloch \& Schneider, 1801); the Mariana goby Awaous guamensis (Cuvier \& Valenciennes, 1837); and the Tahitian prawn Macrobracbium lar (Fabricius, 1798). Stomach contents of these species (except $M$. lar) have been found to contain atyids (R. B. Tibbatts, pers. comm.). Second, to test the effect of predators on atyid distribution directly, we conducted a transplant experiment in the field, involving $K$. rupestris. Kublia are free-swimming, visual predators, occurring only in the lower reaches of rivers, below barrier waterfalls. If predation by Kublia is an important influence on the distribution of atyids in the streams of Guam, then densities of atyid species would be expected to be lower in pools containing transplanted $K$. rupestris than in control pools containing no $K$. rupestris.

\section{MATERIALS AND METHODS}

\section{Study Area}

We collected data from two rivers (Figure 1). The Asmafines River (coordinates at the mouth: lat. $13^{\circ} 19^{\prime} 37^{\prime \prime} \mathrm{N}$, long. $144^{\circ} 39^{\prime} 03^{\prime \prime}$ E) is a high-gradient stream located in the south on Guam's steeper western slope, with a perennial channel length of $1341 \mathrm{~m}$ and an elevation of $134 \mathrm{~m}$ at the headwaters (Best and Davidson 1981). The Ugum River (coordinates at the confluence: lat. $13^{\circ} 20^{\prime} 11^{\prime \prime}$ $\mathrm{N}$, long. $144^{\circ} 45^{\prime} 08^{\prime \prime} \mathrm{E}$ ) is a long, lowgradient stream located in one of the large drainage basins characteristic of the southeast. It is a major tributary of the Talofofo River and has a main channel length of $11,460 \mathrm{~m}$ and an elevation of $183 \mathrm{~m}$ at the headwaters (Best and Davidson 1981). Both rivers are considered relatively undisturbed, but the lower reaches of the Ugum are obstructed by a weir. The weir was built in 1992 by the Public Utility Agency of Guam and is estimated to supply between 7 and 11 million liters of water per day to villages in the southeast (Wiles and Ritter 1993). The effect of this water removal on atyid densities and distribution is poorly understood.

\section{Study Sites and Field Metbodology}

We selected sites with a modified version of the stratified random sampling method of Baker and Foster (1992). Habitat types were classified qualitatively as riffles (areas with current, surface turbulence, and emergent rocks), runs (areas with current, no surface turbulence, and no emergent rocks), and pools (areas with little or no current and no surface turbulence). Three reaches (upper, middle, and lower) were identified in both rivers. The upper reaches were characterized by a steep gradient, short drops, and plunge pools with a rock or boulder substrate, and flanked by dense riparian vegetation. The middle reaches were characterized by a low to medium gradient, substrate dominated by rocks and boulders with some sandy areas, and thinning riparian vegetation. The lower reaches were characterized by slow currents, wide and deep water, and a dominant substrate of sand and/or mud. We intended to choose six sites within each reach (two of each habitat type). However, we did not encounter any pools in the lower reach of the Ugum, and there was a paucity of riffles in both the lower reach of the Ugum and the upper reach of the Asmafines. In addition, during the period of high flow, one run on the lower reach of the Ugum was impossible to survey. We surveyed extra riffles and extra runs (one in place of the missing pool) in the middle and upper reaches of the Ugum. Therefore, we surveyed five riffles, six runs, and six pools on the Asmafines River and seven riffles, seven runs, and five pools on the Ugum River, for a total of 36 sites. Because previous observations indicated that current velocity might have a major effect on atyid distribution (Ellis-Neill 1987), data were collected from the same quadrats (when possible) during periods of low flow (March 1996-May 1996) and high flow (September 1996-January 1997).

We chose sites on both rivers with the aid of a random numbers table. Numbers 


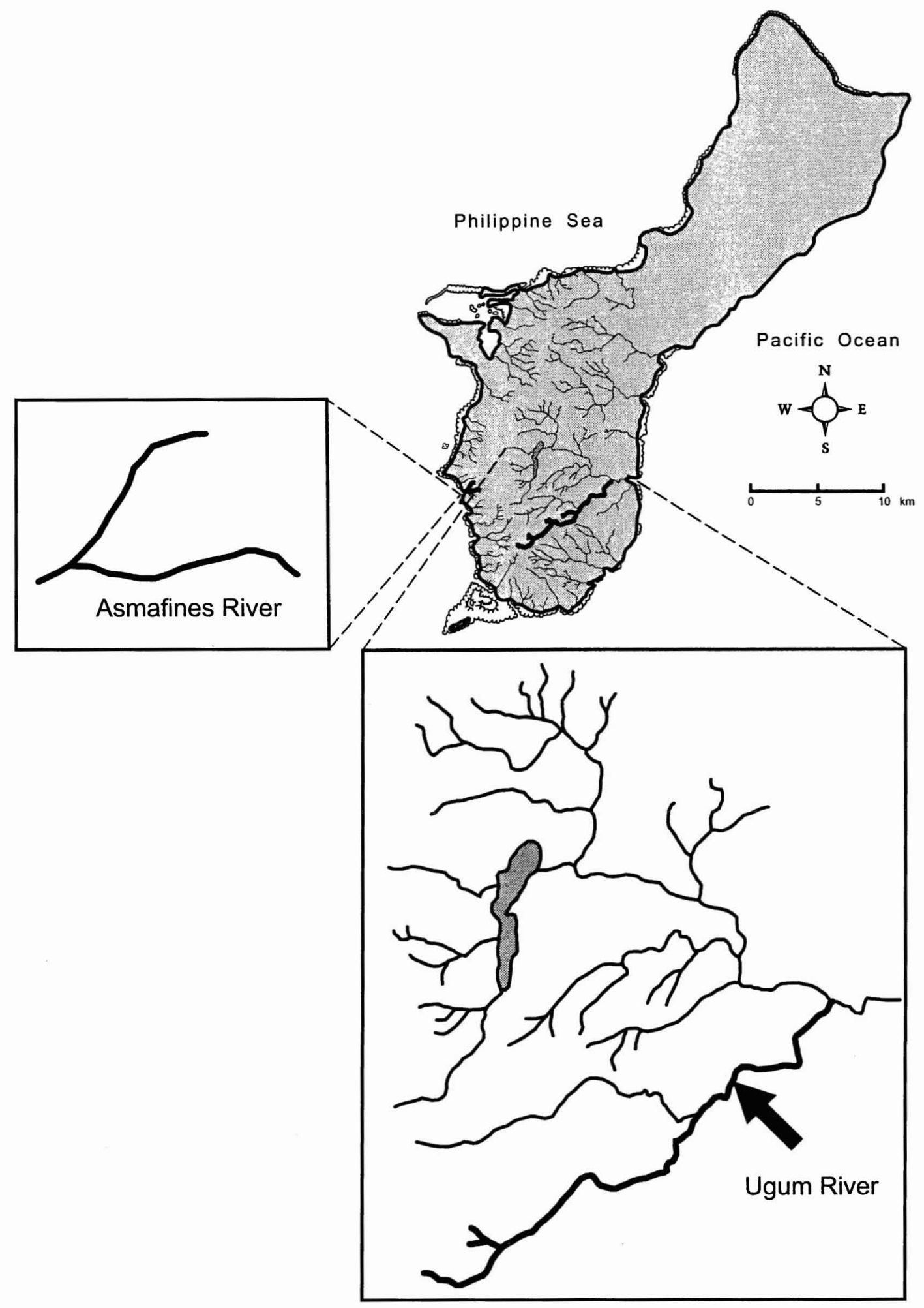

Figure 1. Map of Guam indicating geographic location of study areas. 
selected represented the number of habitat types upstream from access points to the reach. For example, for pools, selection of 3 and 5 indicated that we surveyed the third and fifth pools encountered upstream from the point of access to the reach. Sets of numbers for each type of habitat were selected.

We conducted visual counts in one virtual $2-\mathrm{m}^{2}(1.4$ by $1.4 \mathrm{~m})$ quadrat within each site. We measured the parameters of each quadrat with a tape measure before we began the counts. This quadrat size represented at least $10 \%$ of each site. Because adults of all atyid species are found more frequently near the edges of rivers, we positioned quadrats along the bank, arbitrarily choosing the right side of the river (when facing upstream) and the upstream end of the habitat type. We approached the quadrat from downstream so as not to disturb the shrimp. We performed visual counts while snorkeling in the stream or from the bank. Although adults of Atyoida pilipes can be easily identified in the field, adults of the five species of Caridina resemble one another (Bouvier 1925) and cannot be distinguished without the aid of a microscope. Thus, during visual counts, atyids were identified to genus. Upon completion of visual counts, we collected a subsample of atyids (with a dip net) from the quadrat. We fixed individuals in $80 \%$ ethanol for later identification.

In addition to atyid density, the following variables were evaluated, in each quadrat, at each site: (1) $\mathrm{pH}$; (2) water temperature; (3) maximum depth in quadrat; (4) percentage vegetation cover; (5) substrate type (percentage bedrock; percentage boulders; percentage rubble; percentage gravel; percentage sand; percentage silt); (6) abundance of aquatic vegetation; (7) current velocity; (8) density of Kublia rupestris; (9) density of Anguilla marmorata; (10) density of Awaous guamensis; (11) density of Eleotris fusca; (12) density of Macrobracbium lar; and (13) density of all other gobies combined, including Sicyopterus macrostetholepis (Bleeker, 1853), Sicyopus sp., Stenogobius sp., Stipbodon percnopterygionus Watson \& Chen, 1998, and Stiphodon sp.

We measured $\mathrm{pH}$ with a $\mathrm{pH}$ meter (Sper Scientific Digital 840008) and temperature with a mercury thermometer, both on site. The canopy cover directly over the quadrat was estimated visually to the nearest $10 \%$. We tested this method against the results of a forest densiometer (Robert E. Lemmon Model-C) and found the visual estimate to be accurate and more expedient. The percentage cover of each substratum type was also estimated visually. We categorized substrata as bedrock, boulders (>256 mm; "head sized"), rubble (>64-256 mm; "fist sized"), gravel (>2-64 mm; "thumb sized"), sand (>0.2-2 $\mathrm{mm}$; "grain sized"), and silt (material $2 \mu \mathrm{m}-$ $0.2 \mathrm{~mm}$ that can be suspended in the water column) (modified from Helm et al. 1985). The percentage cover of each substratum type was estimated in one-fourth increments of the quadrat and these increments were assigned the following values: 0, absent; $1,25 \% ; 2,25-50 \% ; 3,50-75 \%$; and 4, 75$100 \%$. We categorized the aquatic vegetation qualitatively as 0 , absent; 1 , present (found in $<50 \%$ of quadrat); or 2, abundant (found in $>50 \%$ of quadrat). Current velocity was measured at the center of the quadrat, at $0.6 \times$ the maximum depth, with a velocity meter (Marsh-McBirney MMI Model 2000 Flo-mate). We determined population densities of other species (variables 8-13) with visual counts, at the same time and in the same way as atyid densities.

\section{Transplant Experiment}

In addition to examining the data with various statistical analyses, we conducted a transplant experiment to test the effect of predation directly. We identified three pairs of pools, each containing comparable atyid densities (determined by separate visual surveys, as described earlier, but of the entire pool), above the barrier waterfall on the Asmafines River. The upstream and downstream access points of these pools were fenced with $3-\mathrm{cm}$ mesh wire. This mesh size was sufficient to contain the Kublia. We did not try to contain the atyids within the pools, because the required mesh size impeded water flow. Containment of atyids is also made difficult by their ability to migrate across moist terrestrial substrate (Jalihal et al. 1994). We then measured atyid 
densities again, using visual surveys, after the screens were in place. Kublia were captured from the lower reaches of the Asmafines River, transferred to the pools in 20-liter buckets, and released. We placed one or two Kublia in each of three randomly selected pools (one from each pair). One each was placed in two pools (area $=5.22 \mathrm{~m}^{2}$, density of Kublia $=0.2$ per square meter; area $=7.30$ $\mathrm{m}^{2}$, density of Kublia $=0.1$ per square meter). We placed two Kublia in another pool $\left(\right.$ area $=17.55 \mathrm{~m}^{2}$, density of Kublia $=0.1$ per square meter). These densities fell within the range of natural densities of Kublia determined in this study (0.0-5.0 per square meter). After $24 \mathrm{hr}$ (the pool with two Kublia) and $48 \mathrm{hr}$ (the other two pools), we used visual surveys to determine atyid densities again for all pools.

\section{Data Analyses}

We performed data analyses with the Statview Statistical System for Macintosh (Abacus Concepts 1995). For all parametric tests, we conducted Levene's test for homogeneity of the variances and performed appropriate transformations as needed. When data did not meet the assumptions of analysis of variance (ANOVA), even after the transformations, appropriate nonparametric tests were conducted (Sokal and Rohlf 1995).

\section{RESULTS}

\section{Environmental Factors}

Figure 2 shows the distribution of atyid species in each river. The densities used in Figure 2 are based on the subsamples collected from each quadrat and are not comprehensive. Different species of Caridina appear to predominate in each river. Caridina typus and $C$. weberi occurred in higher densities in our collections from the Asmafines River, whereas $C$. nilotica was the dominant species in collections from the Ugum River. Densities of Atyoida (determined by visual counts) are significantly lower in the Asmafines River (Mann-Whitney $U$, tied $Z=-2.76, n=34$, tied $P=0.006$ ), but comparable densities of

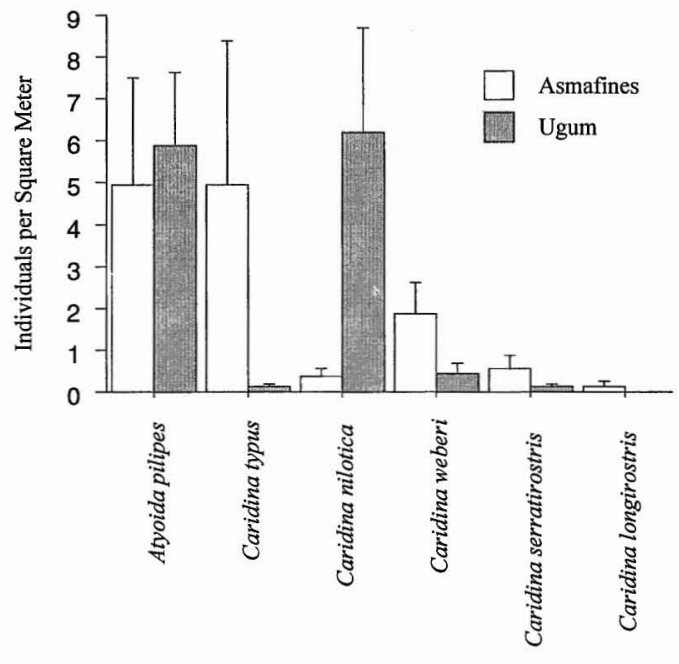

Figure 2. Distribution of six species of atyid shrimp in the Asmafines and Ugum Rivers of Guam. Mean densities were determined from collections of specimens within $0.25-\mathrm{m}^{2}$ areas with a dip net. Capped bars represent standard errors of the means.

Caridina (determined by visual counts) occurred in both rivers (Mann-Whitney $U$, tied $Z=-0.703, n=34$, tied $P=0.48$ ).

We compared each environmental variable with densities of Atyoida and densities of Caridina (Table 1). Although many relationships were not found to be significant, some variables appear to be important influences of atyid distribution. Densities of Atyoida were positively correlated with temperature and aquatic vegetation and negatively correlated with depth (Table 1). Densities of Caridina were positively correlated with depth and negatively correlated with $\mathrm{pH}$ (Table 1$)$. In addition, densities of Atyoida were significantly higher in riffles than in runs and pools (Kruskal-Wallis, $H$ [corrected for ties $]=6.84, n=34$, tied $P=0.03$ ). Conversely, densities of Caridina were significantly higher in runs and pools than in riffles (Kruskal-Wallis, $H$ [corrected for ties] = $8.57, n=34$, tied $P=0.01$ ).

\section{Faunal Interactions}

The effects of faunal interactions on atyid densities and distribution were also analyzed. 
TABLE 1

Correlation $Z$ Tests for Densities of Atyid Genera and Environmental Variables

\begin{tabular}{lll}
\hline \hline Variables & \multicolumn{1}{c}{ Atyoida } & \multicolumn{1}{c}{ Caridina } \\
\hline Canopy cover & $Z=-0.084, n=72, P=0.93$ & $Z=-0.828, n=72, P=0.41$ \\
pH & $Z=-0.463, n=72, P=0.64$ & $Z=-3.483, n=72, P=0.0005^{*}$ \\
Temperature & $Z=2.399, n=72, P=0.017^{*}$ & $Z=-0.708, n=72, P=0.48$ \\
Depth & $Z=-2.453, n=72, P=0.014^{*}$ & $Z=3.31, n=72, P=0.0009^{*}$ \\
Substrate & $Z=0.089, n=72, P=0.93$ & $Z=1.331, n=72, P=0.18$ \\
Aquatic vegetation & $Z=2.440, n=72, P=0.015^{*}$ & $Z=0.001, n=72, P=0.9994$ \\
Current velocity & $Z=1.223, n=72, P=0.22$ & $Z=-1.042, n=72, P=0.30$ \\
\hline
\end{tabular}

* Significant.

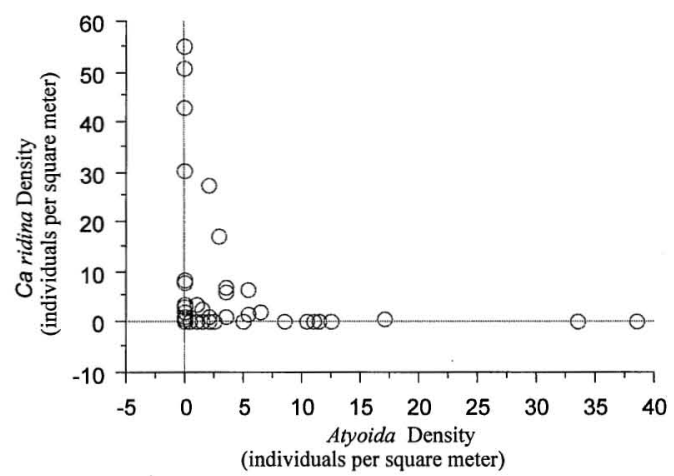

FIGURE 3. Scatterplot of density of Atyoida versus density of Caridina. Densities were determined by visual counts.

Densities of the two atyid genera are negatively correlated, but not significantly so (Correlation $Z$ test, $Z=-0.94, n=72, P=$ $0.35)$. The two genera do not frequently cooccur (Figure 3), which corresponds with their preponderance in different habitats. Densities of atyids were not significantly negatively correlated with predator densities, neither separately nor when all potential predators were combined (Table 2). However, we did not see adult atyids where Kublia occur, in the lower reaches, below the barrier waterfalls. We found only juvenile atyids, buried within gravelly substrata, in habitats containing Kublia.

Measurements of the carapace lengths (from the postorbital edge to the posterior end of the carapace, measured at the midline) of the preserved specimens were taken to compare whether shrimp size distribution reflected atyid amphidromy or the presence of Kublia. Mean shrimp carapace length is significantly larger above the barrier waterfalls than below in both rivers and for all species combined (Kruskal-Wallis, $H$ [corrected for ties] $=86.92, n=171$, tied $P=0.0001)$. In addition, we compared the carapace lengths

TABLE 2

Correlation Z Tests for Densities of Atyid Genera and Predator Densities

\begin{tabular}{lcc}
\hline \hline Variables & Atyoida & Caridina \\
\hline Kublia rupestris & $Z=-1.243, n=72, P=0.21$ & $Z=-1.023, n=72, P=0.31$ \\
Anguilla marmorata & $Z=-0.612, n=72, P=0.54$ & $Z=0.008, n=72, P=0.99$ \\
Awaous guamensis & $Z=-0.738, n=72, P=0.46$ & $Z=0.045, n=72, P=0.96$ \\
Eleotris fusca & $Z=-0.612, n=72, P=0.54$ & $Z=-0.312, n=72, P=0.75$ \\
Macrobrachium lar & $Z=-0.392, n=72, P=0.70$ & $Z=0.759, n=72, P=0.45$ \\
All predators combined & $Z=-0.949, n=72, P=0.34$ & $Z=0.455, n=72, P=0.65$ \\
\hline
\end{tabular}

* Significant. 
(for all species combined) from sites nearest the top of the barrier waterfalls on each river with those from sites farther upstream. There was no significant difference between sites (Mann-Whitney $U$, tied $Z=-0.356, n=$ 129, tied $P=0.72$ ).

\section{Transplant Experiment}

We conducted a transplant experiment involving Kublia to test directly their importance as predators on atyids. Before we transplanted Kublia, all experimental and control pools contained atyids at densities from 0.92 to 1.32 per square meter. We saw no atyids in pools containing transplanted Kublia. Conversely, atyid densities in control pools did not differ significantly during the experiment (paired $t$-test, $t=-1.999$, $\mathrm{df}=2$, $P=0.184$ ). After the experiment, barriers were removed and after a few months of heavy rains, the experimental pools were checked again. No Kublia remained in these pools, and natural densities of atyid shrimp had returned.

\section{DISCUSSION}

We found Atyoida and Caridina in different habitats. The two genera were also correlated with different environmental variables (Table 1). Atyoida were seen mainly in riffles, which contain shallower water. This corresponds with their negative correlation with depth. They were positively correlated with both temperature and aquatic vegetation, which were both significantly higher in the dry season than during the rainy season (one-way ANOVA, $F=21.32, \mathrm{df}=70, P=0.0001$; one-way ANOVA, $F=7.75, \mathrm{df}=70, P=$ 0.007 , respectively). Densities of Atyoida were also higher in the dry season, but not significantly so (Mann-Whitney $U$, tied $Z=$ $-1.524, n=72$, tied $P=0.13$ ). Caridina were found more often in runs and pools, both associated with deeper water. This is supported by their positive correlation with depth. They were also negatively correlated with $\mathrm{pH}$, which was significantly higher in the Asmafines River, due to the presence of a limestone cap located above the river (one-way
ANOVA, $F=50.92, \mathrm{df}=70, P=0.0001$ ). Conversely, densities of Caridina were lower in the Asmafines, but not significantly so (Mann-Whitney $U$, tied $Z=-0.703, n=34$, tied $P=0.48$ ).

The association of Atyoida with riffle areas and Caridina with runs and pools is similar to the findings of Chace (1983) and Ellis-Neill (1987), but contrasts with those of Bright (1989). This habitat differentiation is unlikely to be the result of either interference or exploitation competition. The two genera are not obviously aggressive toward each other in places where they do coexist (pers. obs.). They are both detritivores, and thus their food supply is probably not limited (Couret 1976). Their predominance in different habitats corresponds with morphological adaptations to these habitats. Atyoida possess longer setae appropriate for filter feeding in higher velocity water (Couret 1976, Chace 1983, Ellis-Neill 1987), whereas Caridina have both short and long setae appropriate for filtering or scraping in a wider range of habitats (Bouvier 1925, Ellis-Neill 1987).

We saw no negative correlation between atyid and individual or combined predator densities. However, two known predators, Anguilla marmorata and Eleotris fusca, were almost certainly underrepresented in the visual surveys. Anguilla marmorata is more active at night and E. fusca is highly cryptic, found most frequently under cover, and specializes in ambushing its prey. On Guam Awaous guamensis is most often seen feeding in areas with soft substrates, and, although atyids have been found in their stomach, their gut contents mainly comprise algae, sand, and occasionally, other invertebrates (R. B. Tibbatts, pers. comm.). Moreover, all of these predatory fishes are present throughout the river, co-occurring with atyids. Wellborn and Robinson (1991), through predator exclusion experiments in a Texas reservoir, concluded that predation by fish does not substantially affect abundances of macroarthropods that naturally co-occur with them. They suggested that these macroarthropods possess antipredator defenses. Atyids may escape predation by $A$. marmorata, $E$. fusca, and $A$. guamensis to a certain extent by reducing 
activity at night (to avoid $A$. marmorata) and by occupying relatively exposed, hard substrata during the day (to avoid $E$. fusca and A. guamensis). The prawn Macrobrachium lar also occurs with both genera of atyids in high densities and has not been seen to consume them, neither in the field nor in laboratory aquariums (pers. obs.). This contrasts with the findings of Couret (1976) and Crowl and Covich (1994), which demonstrated that prawns in the genus Macrobracbium prey upon atyids in Hawai'i and Puerto Rico, respectively. However, in Hawai'i, Macrobracbium lar is an introduced species.

Predation by Kublia appears to be a factor influencing atyid distribution. The jungle perch Kublia rupestris is the only predator that does not co-occur with adult atyids, and it was shown to have a considerable effect on atyids in our transplant experiment. This differs with the results of exclusion/inclusion experiments in temperate areas. For example, Allan (1982) found that a reduction in trout densities in streams in Colorado did not result in a significant increase in densities of benthic invertebrates. Similarly, Reice and Edwards (1986) conducted both exclusion and inclusion experiments in two Canadian streams (one that naturally contains fish and one that does not) and concluded that brook trout do not have a major effect on the distribution of benthic invertebrate communities in those streams. Gilinsky (1984) reported mixed results from exclusion and inclusion experiments with bluegill sunfish in a North Carolina pond. She found that the effect of fish predation on benthic macroinvertebrates was dependent on season and habitat complexity. However, Fraser et al. (1995) performed both inclusion and exclusion experiments in streams on the tropical island of Trinidad and found that in areas split by barrier waterfalls, predators can produce disjointed prey distributional patterns, by both consumption and by causing prey to ascend cascades. In addition, Reznick et al. (1997) moved guppies from pools with many predators below barrier waterfalls into pools with only one predator above waterfalls in Trinidadian rivers. The guppies exposed to less predation matured at a larger size at a later age and produced fewer, larger young.

The results of the transplant experiment in our study suggest either a behavioral response by the atyids, such as hiding or migrating to adjacent areas, or consumption by Kublia, or both. Analysis of stomach contents of recaptured Kublia would have been helpful in confirming the latter, but we could not recapture Kublia with methods that are nondestructive to the stream ecosystem. Laboratory experiments involving Kublia and atyids might prove useful in determining to what extent shrimp can hide or escape and to what extent they are eaten.

The influence of Kublia on atyid distribution is also supported by the difference in shrimp carapace length from below and above the waterfalls. We found that only small atyids buried within substrata occur with Kublia. If differences in carapace length reflect the amphidromous lifestyle of atyids instead of the influence of Kublia, a gradual increase in size might be expected as distance from the mouth of the river increases. However, carapace length was not significantly larger in sites farther from the top of the waterfalls than in sites closest to the top of the waterfalls. This suggests that Kublia are an influence on atyid size distribution.

Although habitat characteristics appear to be a major factor affecting the distribution of atyid shrimps in the streams of Guam, our transplant experiment also illustrated the importance of predation by the jungle perch Kublia rupestris on atyid distribution.

\section{ACKNOWLEDGMENTS}

We thank Frank Camacho, Michelle Gaither, and Brent Tibbatts for their assistance in the field and for their much-appreciated senses of humor. We wish also to express gratitude to the faculty, staff, and graduate students at the University of Guam Marine Laboratory. We thank Rosemary Leberer for locating references unavailable to us. Robert Rowan provided valuable editorial comments on the manuscript. Finally, we thank Greg Fulcher for his support. 


\section{Literature Cited}

Abacus Concepts. 1995. Statview Statistical System for Macintosh. PowerPC version. Abacus Concepts, Berkeley, California.

Allan, J. D. 1982. The effects of reduction in trout density on the invertebrate community of a mountain stream. Ecology 63:1444-1455.

Baker, J. A., and S. A. Foster. 1992. Estimating density and abundance of gobies in Hawaiian streams. Rep. Hawaii Div. Aquat. Res.

Benzie, J. A. H. 1982. The complete larval development of Caridina mccullochi Roux, 1926 (Decapoda, Atyidae) reared in the laboratory. J. Crustacean Biol. 2:493-513.

Best, B. R., and C. E. Davidson. 1981. Inventory and atlas of the inland aquatic ecosystems of the Marianas Archipelago. Univ. Guam Mar. Lab. Tech. Rep. 75.

Bouvier, E.-L. 1925. Recherches sur la morphologie, les variations, la distribution géographique des crevettes de la famille des Atyidés. Encycl. Entomol. 4:1-370.

Bright, G. R. 1979. The inland waters of Palau, Caroline Islands. Office of the Chief Conservationist, Trust Territory of the Pacific Islands, Palau.

. 1989. The freshwater decapod crustaceans of Yap, Caroline Islands. Pages 33-36 in S. G. Nelson, ed. The inland aquatic habitats of Yap. University of Guam Marine Laboratory, Mangilao, Guam.

Carpenter, A. 1983. Population biology of the freshwater shrimp Paratya curvirostris (Heller, 1862) (Decapoda: Atyidae). N. Z. J. Mar. Freshwater Res. 17:147-158.

Chace, F. A., Jr. 1983. The Atya-like shrimps of the Indo-Pacific region (Decapoda: Atyidae). Smithson. Contrib. Zool. 384.

Couret, C. L., Jr. 1976. The biology and taxonomy of a freshwater shrimp, Atya bisulcata Randall, endemic to the Hawaiian Islands. M.S. thesis, University of Hawai'i at Mānoa, Honolulu.

Crowl, T. A., and A. P. Covich. 1994. Responses of a freshwater shrimp to chemical and tactile stimuli from a large decapod predator. J. North Am. Benthol. Soc. 13:291-298.

De Silva, K. H. G. M. 1988. Studies on Atyidae (Decapoda, Caridea) of Sri Lanka. III. Aspects of the population ecology of Caridina simoni Bouvier, 1904. Crustaceana (Leiden) 54:85-103.

Dudgeon, D. 1985. The population dynamics of some freshwater carideans (Crustacea: Decapoda) in Hong Kong, with special reference to Neocaridina serrata (Atyidae). Hydrobiologia 120:141-149.

Ellis-Neill, L. 1987. Distributional and production dynamics of benthic invertebrates in a tropical stream on Guam. M.S. thesis, University of Guam, Guam.

Fraser, D. F., J. F. Gilliam, and T. Yip-Hoi. 1995. Predation as an agent of population fragmentation in a tropical watershed. Ecology 76:1461-1472.

Gilinsky, E. 1984. The role of fish predation and spatial heterogeneity in determining benthic community structure. Ecology 65:455-468.

Hart, R. C. 1981. Population dynamics and production of the tropical freshwater shrimp Caridina nilotica (Decapoda: Atyidae) in the littoral of Lake Sibaya. Freshwater Biol. 11:531-547.

Helm, W. T., P. Brouha, M. Aceituna, C. Armour, P. Bisson, J. Hall, G. Holton, and M. Shaw. 1985. Glossary of stream habitat terms. Western Division, American Fisheries Society.

Jalihal, D. R., G. B. Almelkar, and K. N. Sankolli. 1994. Atyid shrimps of the genus Caridina H. Milne Edwards, 1837: Potential crustacean material for experimental biology. Crustaceana (Leiden) 66:178183.

Reice, S. R., and R. L. Edwards. 1986. The effect of vertebrate predation on lotic macroinvertebrate communities in Québec, Canada. Can. J. Zool. 64:1930-1936.

Reznick, D. N., F. H. Shaw, F. H. Rodd, and R. G. Shaw. 1997. Evaluation of the rate of evolution in natural populations of guppies (Poecilia reticulata). Science (Washington, D.C.) 275:1934-1937.

Shokita, S. 1976. Early life-history of the 
land-locked atyid shrimp, Caridina denticulata ishigakiensis Fujino et Shokita, from the Ryukyu Islands. Res. Crustacea, Carcinol. Soc. Jpn. 7:1-10.

Sokal, R. R., and F. J. Rohlf. 1995. Biometry: The principles and practice of statistics in biological research, 3d ed. W. H. Freeman and Company, New York.

Wellborn, G. A., and J. V. Robinson. 1991.
The influence of fish predation in an experienced prey community. Can. J. Zool. 69:2515-2522.

Wiles, G. J., and M. W. Ritter. 1993. Guam. Pages 129-178 in D. A. Scott, ed. A directory of wetlands in Oceania. IWRB, Slimbridge, U.K., and AWB, Kuala Lumpur, Malaysia. 